\title{
Airway Obstruction due to Mucus Plug in Patients with Organophosphorus Poisoning- Atropine the Culprit? A Case Series
}

\author{
Sajjan Prashant Shivaraj ${ }^{1 *}$, Kulkarni Vandana Sharashchandra ${ }^{2}$ \\ ${ }^{1,2}$ Associate Professor Aarupadai Veedu Medical College, Puducherry, India 607403 \\ Organophosphorus poisoning is a common cause of death in developing countries. These \\ compounds inhibit acetylcholinesterase leading to accumulation of acetylcholine, causing \\ overstimulation of nicotinic and muscarinic receptors. Atropine and oximes are the \\ mainstay of treatment. Atropine helps in countering muscarinic effects and decreasing \\ secretions. It also makes the secretions thick, tenacious and may obstruct the airway. We \\ observed five cases of organophosphorus poisoning being treated with atropine developing \\ sudden respiratory distress attributed to mucus plug obstructing the airway which was \\ confused with intermediate syndrome. After removal of the mucus plug these patients \\ recovered uneventfully.
}

Keywords: atropine, organophosphorus poisoning, respiratory distress, mucus plug, airway obstruction.

\section{Introduction}

Primary mechanism of organophosphorus (OP) toxicity is inhibition of acetylcholinesterase in central and peripheral nervous systems, causing accumulation of acetylcholine at nicotinic and muscarinic receptors. ${ }^{1}$ Action on muscarinic receptors causes increased salivation, bradycardia, lacrimation, emesis, and miosis $^{2}$.Atropine counters muscarinic effects and decreases secretions. ${ }^{3}$ However, it makes secretions thick and viscous, which are difficult to swallow in patients with muscle weakness and also difficult to remove by suction.

We report five cases of OP poisoning, where we strongly suspect that use of atropine could be the culprit, leading to mucus plug formation and airway obstruction.

\section{Case Report}

Out of 150 cases of suicidal OP poisoning admitted to a tertiary care hospital and managed for various levels of toxicity and complications,

*Correspondence: Sajjan Prashant Shivaraj

E mail: drdrdrprashant@rediffmail.com

https://orcid.org/0000-0002-9375-3487

Received: $26 / 07 / 2020$

Accepted: 17/09/2020

DOI: http:/doi.org/10.4038/slja.v29i1.8645 including intermediate syndrome over a five years period, we report five cases which developed respiratory distress. (Table 1)

OP poisoning was diagnosed based on positive history of ingestion and characteristic smell. The patients presented between 30-60 minutes of ingestion (mean $45 \pm 15 \mathrm{~min}$ ) with nausea, vomiting and sweating. Supportive measures like stomach wash, body wash, humidified oxygen and intravenous fluids were initiated.

Blood sample was drawn for routine investigations and pseudocholinesterase (PChE) estimation. Haemodynamics (mean $\pm \mathrm{SD}$ ) on admission were heart rate (HR) $68.2 \pm 3.03$ beats per minute (bpm), $\mathrm{SpO}_{2} 94.6 \pm 2.4 \%$, respiratory rate (RR) $17.4 \pm 1.94 / \mathrm{min}$ and mean arterial pressure $86 \pm 9.22 \mathrm{mmHg}$.

Initial treatment consisted of loading dose of Inj. Pralidoxime $1 \mathrm{~g}$ and Inj. Atropine 1-3mg, intravenously. Monitoring of patients was continued. Dose of atropine was doubled as per institutional protocol (every 3 to $5 \mathrm{~min}$ ) till target heart rate between $110-120$ bpm was reached. After this atropine infusion was started at $10-20 \%$ of the bolus given.

Patients were assessed every $15 \mathrm{~min}$ for features of atropinization (heart rate $>110 \mathrm{bpm}$, clear chest). Intravenous fluids were continued based on haemodynamics and urine output was monitored. Regular suctioning of oral cavity was done. Patients were also monitored for 
development of intermediate syndrome and atropine toxicity.

During $3^{\text {rd }}$ to $5^{\text {th }}$ days (mean 4.2 days) of ICU stay, these patients developed sudden difficulty in breathing, tachypnoea (RR 32.4 $\pm 2.07 / \mathrm{min}$ ), tachycardia (HR 121.4 $\pm 3.84 / \mathrm{bpm}$ ), use of accessory muscles of breathing and oxygen desaturation $\quad(79.8 \pm 1.83 \%)$. Suspecting intermediate syndrome, intubation was planned. During laryngoscopy, mucus plug blocking the airway was observed over the vocal cords.

\section{Table 1}

Details of Patients, Poisoning and Management

\begin{tabular}{|l|l|l|l|l|l|}
\hline Parameters & Case 1 & Case 2 & Case 3 & Case 4 & Case 5 \\
\hline Age (Years) & 20 & 27 & 37 & 50 & 63 \\
\hline Sex & Male & Male & Female & Male & Male \\
\hline History of Smoking & No & Yes & No & Yes & No \\
\hline Compound consumed & $\begin{array}{l}\text { Methyl } \\
\text { parathion }\end{array}$ & $\begin{array}{l}\text { Ethyl } \\
\text { parathion }\end{array}$ & $\begin{array}{l}\text { Ethyl } \\
\text { parathion }\end{array}$ & $\begin{array}{l}\text { Methyl } \\
\text { parathion }\end{array}$ & $\begin{array}{l}\text { Methyl } \\
\text { parathion }\end{array}$ \\
\hline $\begin{array}{l}\text { Ingested Quantity (ml) } \\
\text { (approximately) }\end{array}$ & 50 & 75 & 50 & 100 & 75 \\
\hline $\begin{array}{l}\text { PChE levels on Admission } \\
\text { At Intubation } \\
\text { (Normal range- 5,000-15,000IU/L) }\end{array}$ & 1410 & 1670 & 2080 & 1370 & 1250 \\
\hline Total dose of Atropine (mg) & 430 & 1540 & 1950 & 1290 & 1200 \\
\hline $\begin{array}{l}\text { Presentation of Respiratory } \\
\text { Distress } \\
\text { (Hours after admission) }\end{array}$ & 96 & 450 & 256 & 580 & 514 \\
\hline \begin{tabular}{l} 
Duration of ICU stay (days) \\
\hline
\end{tabular} & 9 & 114 & 74 & 82 & 112 \\
\hline
\end{tabular}

\section{Figure 1(a)}

Mucus Plug covering the vocal cords at the time of intubation

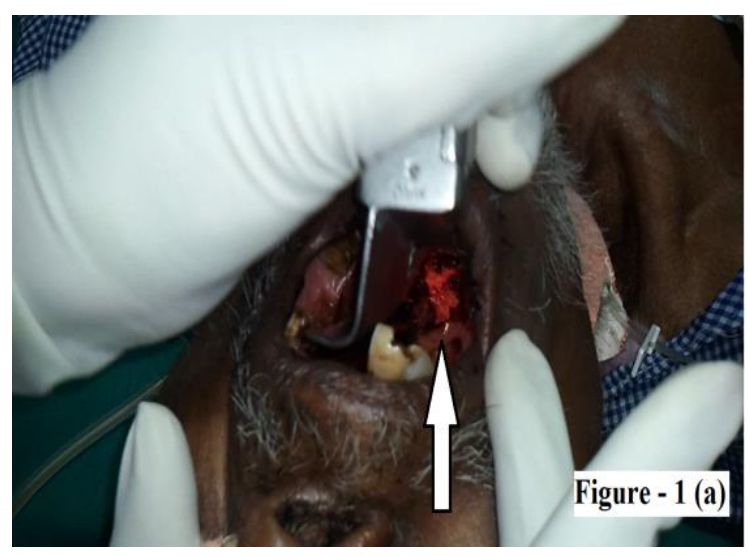

Figure 1(b)

Visible vocal cords after removal of mucus plug

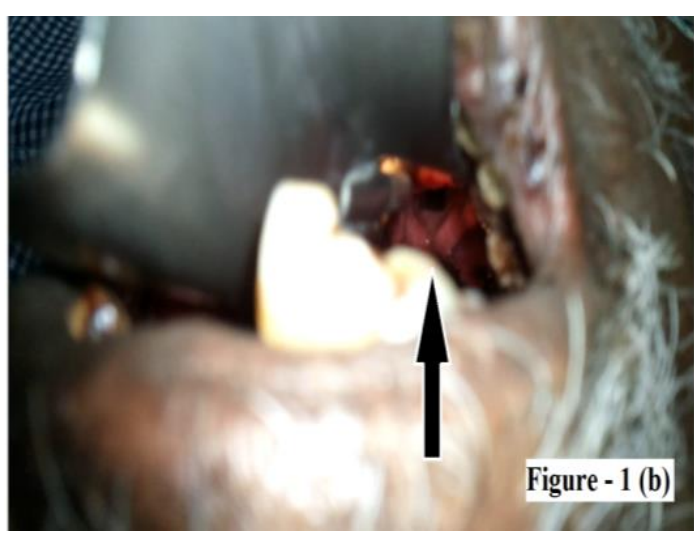




\section{Figure 2}

Mucus plug removed during Intubation

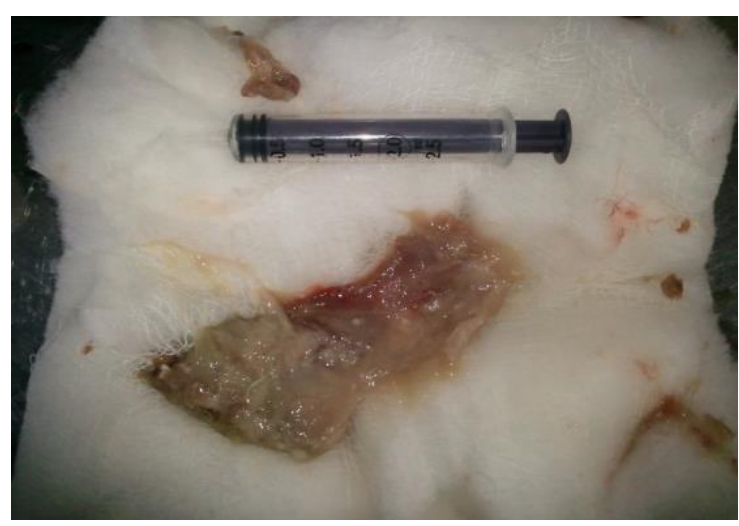

The thick mucus plug could not be sucked out and was removed by Magill's forceps. Patients were intubated and mechanically ventilated. Blood samples were collected for PChE estimation. Atropine infusion was continued, but rate was decreased by $20 \%$ of the ongoing rate. All five patients improved over 4 to 6 hours after the incident with no further adverse respiratory episodes. The patients were extubated 24hours later, after confirmation of consciousness, adequacy of muscle power and haemodynamic stability. Chest $\mathrm{x}$-rays were taken before extubation. Atropine was subsequently tapered and stopped.

\section{Discussion}

Atropine blocks production of respiratory secretions in response to cholinergic stimulation but has no effect on the baseline secretions. It has also been clearly demonstrated to depress ciliary beat frequency, to slow airway mucociliary clearance which can reduce large airway mucus transport and make the secretions thick and tenacious. ${ }^{4,5}$

The mean dose of atropinization in these patients was $11.6 \pm 3.28 \mathrm{mg}$ and mean dose infused hourly was $3.31 \pm 0.78 \mathrm{mg}$. The mean total dose of atropine received was $446 \pm 121.4 \mathrm{mg}$, with mean duration of $139.2 \pm 49.18$ hours. Studies show that the dose of atropine cannot be fixed and is variable with a wide range between $150 \mathrm{mg}$ to $1100 \mathrm{mg}$ during management of OP poisoning. ${ }^{6}$ Mean atropine dose in our patients was within this range. Based on clinical suspicion, the dose of atropine was decreased by $20 \%$ after intubation as the thick mucus plug causing airway obstruction and necessitating intubation was attributed to atropine effect with no other classical signs of overdose such as confusion, pyrexia, absent bowel sounds. ${ }^{2}$

The sudden respiratory distress observed was initially suspected to be due to intermediate syndrome which is common between 1 to 4 days after OP compound consumption. But recovery of patients after removal of the mucus plug within 24hours indicates the absence of intermediate syndrome in which muscle weakness generally persists for an average of $4-$ 18 days. $^{7}$ Mask ventilation with high flow oxygen, non-invasive ventilation or insertion of a supraglottic airway device to maintain the airway after removal of mucus plug may have been considered to avoid intubation and ventilation. However, due to acuteness of the condition with rapid desaturation, and as intermediate syndrome was suspected, endotracheal intubation was performed and mechanical ventilation commenced. The mean PChE level on admission was $1556 \pm 330.57$ IU/L and at the time of respiratory distress, $1471 \pm 295.64 \mathrm{IU} / \mathrm{L}$, which confirms that the deterioration was not related to OP poisoning. ${ }^{8}$

Endotracheal tube blockage in mechanically ventilated patients is a well-known risk, especially so in those patients on atropine because of drying up of bronchial secretions. Lung collapse due to mucus plug formation in three cases of OP poisoning being treated with Inj. glycopyrrolate has also been described. ${ }^{9}$

In smokers muco-ciliary activity is inhibited and viscoelastic properties of mucus change..$^{10}$ The two patients with history of smoking did not have any history of bronchitis or COPD and were not on any anticholinergic medication. We did not find any difference in the time of respiratory distress in these patients and hence could not hypothetically relate the incident to smoking.

The chest X-ray taken prior to extubation was normal indicating there was no underlying lung pathology for the sudden occurrence of respiratory distress. After extubation, patients continued to receive atropine at lower doses. We did not observe any recurrence of mucus plug formation causing respiratory distress post extubation.

\section{Conclusion}

Atropine used in the management of $\mathrm{OP}$ poisoning may be a causative factor in airway obstruction, with potential for producing 
respiratory distress. Observation and anticipation of this rare effect in non- intubated atropinised patients is important as it can be easily confused with intermediate syndrome.

\section{References}

1. Aardema H, Meertens JH, Ligtenberg JJ, PetersPolman OM, Tulleken JE, Zijlstra JG. Organophosphorus pesticide poisoning: cases and developments. Neth J Med. 2008;66(4): 14953.

PMID: 18424861

2. Eddleston M, Buckley NA, Eyer P, Dawson AH. Management of acute organophosphorus pesticide poisoning. Lancet. 2008; 371(9612):597-607.

https://doi.org/10.1016/s0140-6736(08)60947-2 PMID: 17706760

3. Chung SP, Roh HK. Antidote for organophosphate insecticide poisoning: atropine and pralidoxime. J Korean Med Assoc. 2013; 56(12): 1057-1066. https://doi.org/10.5124/jkma.2013.56.12.1057

4. Adam Wanner. Effect of ipratropium bromide on airway mucociliary function. Am J Med. 1986; 81(5): $23-27$ https://doi.org/10.1016/0002-9343(86)90458-4 PMID: 2947458

5. R. Balsamo, L. Lanata, C.G. Egan. Muco-active drugs. Eur Respir Rev. 2010;19(116):127-133. https://doi.org/10.1183/09059180.00003510

PMID: 20956181

6. Ahmed, A., Basher, A., Amin, M., Faiz, M. Effect of Intensive Atropine Doses (Rapid Incremental Loading and Titration) for Management of Organophosphorus Pesticide Poisoning: a Case Series. Asia Pacific Journal of Medical Toxicology, 2014; 3(1): 23-26.

https://doi: 10.22038/apjmt.2014.2466

7. Ahmed SM, Das B, Nadeem A, Samal RK. Survival pattern in patients with acute organophosphate poisoning on mechanical ventilation: A retrospective intensive care unitbased study in a tertiary care teaching hospital. Indian J Anaesth. 2014; 58: 11-17. https://doi.org/10.4103/0019-5049.126780

8. Kumar SV, Fareedullah MD, Sudhakar Y, Venkateswarlu B, Kumar EA. Current review on organophosphorus poisoning. Arch Appl Sci Res. 2010; 2: 199-215.

https://doi.org/10.1007/s12012-011-9104-4

9. Krupesh N, Chandrashekar T R, Ashok A C. Organophosphorus poisoning - still a challenging proposition. Indian J Anaesth. 2002; 46(1): 4043.

10. Baby MK, Muthu PK, Johnson P, Kannan S. Effect of cigarette smoking on nasal mucociliary clearance: A comparative analysis using saccharin test. Lung India. 2014; 31(1): 39-42. https://doi:10.4103/0970-2113.125894 PMID: 24669080 